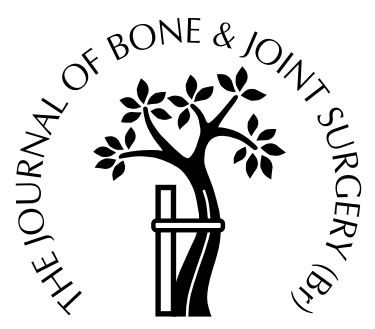

\title{
Dorsal root ganglion neurones with dichotomising afferent fibres to both the lumbar disc and the groin skin
}

\author{
A POSSIBLE NEURONAL MECHANISM UNDERLYING REFERRED \\ GROIN PAIN IN LOWER LUMBAR DISC DISEASES
}

\author{
H. Sameda, Y. Takahashi, K. Takahashi, T. Chiba, S. Ohtori, H. Moriya \\ From Chiba University, Japan
}

$\mathbf{D}^{\circ}$ orsal root ganglion neurones with dichotomising axons are present in several species and are considered to play a role in referred pain. Clinically, patients with lesions in the lower lumbar discs occasionally complain of pain in the groin. We investigated the existence of dichotomising afferent neurones projecting axons both to the lumbar disc and to the groin skin, using the double fluorescent-labelling technique in rats.

We observed neurones labelled with a tracer applied at the ventral portion of the L5-L6 disc and another tracer placed on the groin skin in L1 and L2 dorsal root ganglia. Our results showed that the double-labelled neurones had peripheral axons which dichotomised into both the L5-L6 disc and the groin skin, indicating the convergence of afferent sensory information from the disc and groin skin. Our findings provide a possible neuroanatomical mechanism for referred groin pain in patients with disc lesions.

J Bone Joint Surg [Br] 2003;85-B:600-3.

Received 4 March 2002; Accepted after revision 14 October 2002

Patients who have a degenerative disc in the lower lumbar segments sometimes complain of pain in the groin, which is outside the dermatome of the injured nerve roots. ${ }^{1-3}$ For example, patients with disc herniation may complain of such pain with those having L4-L5 herniation being the most likely to experience this. ${ }^{3}$ In addition, some reports indicate that diagnostic spinal infiltrations when applied to the disc, posterior longitudinal ligament, facet joint, inter-

H. Sameda, MD, PhD, Orthopaedic Surgeon

Y. Takahashi, MD, PhD, Orthopaedic Surgeon

K. Takahashi, MD, PhD, Lecturer

S. Ohtori, MD, PhD, Orthopaedic Surgeon

H. Moriya, MD, $\mathrm{PhD}$, Professor of Orthopaedics

Department of Orthopaedic Surgery

T. Chiba, MD, PhD, Professor of Anatomy

Department of Anatomy

School of Medicine, Chiba University, 1-8-1 Inohana, Chuo-ku, Chiba 2608677, Japan.

Correspondence should be sent to Dr H. Sameda.

(C)2003 British Editorial Society of Bone and Joint Surgery doi:10.1302/0301-620X.85B4.13306 \$2.00 spinous ligaments or other structures can trigger groin pain in some patients. ${ }^{4-10}$

Dorsal root ganglion (DRG) neurones, labelled with two types of tracer transported from different sites in the body, have been found in different areas of the body in several species. ${ }^{1-17}$ Primary sensory fibres in which the peripheral axon bifurcates immediately distal to the DRG to send each branch to two remote different tissues are termed 'dichotomising sensory fibres'. Electrophysiological techniques also demonstrate dichotomising sensory fibres in peripheral nerves. ${ }^{18-21}$ Thus, such nerve fibres are a possible substratum of referred pain. ${ }^{11,22}$ So far, however, most investigations of DRG neurones with dichotomising axons have been in visceral organs and not in the spine. ${ }^{11,13,14,16,20,21}$

Chemical noxious stimulation of the lower lumbar intervertebral discs has been found to cause extravasation of plasma in the groin skin, which is in the L2 dermatome. ${ }^{23}$ Dichotomising unmyelinated fibres contained in the L2 spinal nerve, or a spinal vascular reflex through sympathetic efferents, may induce the plasma extravasation. ${ }^{23}$ Recent investigations of lumbar disc innervation using neural tracers found the presence of sensory neurones innervating the ventral portion of the L5-L6 lumbar intervertebral disc in L1 and L2 in rats. ${ }^{2}$

Our aim therefore was to investigate DRG neurones with dichotomising axons projecting both to the lumbar intervertebral disc and to the groin area using the double fluorescent- labelling technique.

\section{Materials and Methods}

We anaesthetised 20 male Sprague-Dawley rats weighing 250 to $360 \mathrm{~g}$ with an intraperitoneal injection of sodium pentobarbital $(50 \mathrm{mg} / \mathrm{kg})$ and prepared them for aseptic surgery.

Application of tracer to the ventral portion of the disc. With the rat supine, after an initial midline abdominal incision, we incised the retroperitoneum along the left margin of the aorta, and exposed the ventral surface of the L5-L6 intervertebral disc between the aorta and the left psoas muscle under an operating microscope. A 21-gauge needle, with a cut tip filled with crystals of $1,1^{\prime}$-dioctadecyl3,3,3', 3' -tetramethyl-indocarbocyanine perchlorate (DiI; Molecular Probes Inc, Eugene, Oregon) was advanced 0.5 
Table I. Total numbers of DiI-, FG- and DiI/FG double-labelled neurones in left DRGs T12 to S1 from ten rats which had FG applied to the ventral rami of the T12 to S1 spinal nerves

\begin{tabular}{|c|c|c|c|c|c|}
\hline DRG & $\begin{array}{l}\text { Number of } \\
\text { DiI-labelled } \\
\text { neurones }\end{array}$ & $\begin{array}{l}\text { Number of } \\
\text { FG-labelled } \\
\text { neurones }\end{array}$ & $\begin{array}{l}\text { Number of DiI/FG } \\
\text { double-labelled } \\
\text { neurones }\end{array}$ & $\begin{array}{l}\text { Double-labelled } \\
\text { neurones in DiI-labelled } \\
\text { neurones }(\%)\end{array}$ & Range (\%) \\
\hline $\mathrm{T} 12$ & 0 & 407 & 0 & - & \\
\hline $\mathrm{T} 13$ & 6 & 561 & 0 & 0.0 & \\
\hline L1 & 69 & 2403 & 3 & 4.3 & 0 to 33.3 \\
\hline L2 & 63 & 2512 & 6 & 9.5 & 0 to 40.0 \\
\hline L3 & 23 & 1943 & 0 & 0.0 & \\
\hline L4 & 4 & 1218 & 0 & 0.0 & \\
\hline L5 & 8 & 563 & 0 & 0.0 & \\
\hline L6 & 0 & 265 & 0 & - & \\
\hline $\mathrm{S} 1$ & 0 & 204 & 0 & - & \\
\hline Total & 173 & 10076 & 9 & 5.2 & \\
\hline
\end{tabular}

$\mathrm{mm}$ from the ventral surface of the disc to allow the tip to be located in the ventral portion of the disc. Sealing the needle with cyanoacrylate prevented leakage of DiI. Finally, we sutured both the peritoneum and skin.

Tracer application to the skin. Three weeks after the application of DiI to the disc, using a razor blade, we made cutaneous incisions parallel to the craniocaudal midway lines of the left T12 to S1 dermatomes, ${ }^{24}$ taking care to confine the incision within the skin. A solution of 5\% (W/V) FluoroGold (FG; Fluorochrome Inc, Denver, Colorado) dissolved in saline was applied to the incisions. In ten rats this was to the part innervated by the ventral and in another ten to that innervated by the dorsal rami of the T12 to S1 spinal nerves. Microbiological observation and analysis. One week after the application of FG the rats were anaesthetised with pentobarbital and perfused transcardially with saline $(0.9 \%)$, followed by paraformaldehyde $(500 \mathrm{ml}$ of $4 \%)$ in phosphate buffer $(0.1 \mathrm{M}, \mathrm{pH} 7.4)$. We resected bilateral DRGs from T12 to S1. Examination of all the rats confirmed the confinement of DiI to the ventral portion of the disc with no leakage to the outside during the fixation process. After immersion of the DRGs in the same fixative overnight at $4^{\circ} \mathrm{C}$, and storage in $0.01 \mathrm{M}$ phosphate buffered saline containing $20 \%(\mathrm{~W} / \mathrm{V})$ sucrose for 24 hours at $4^{\circ} \mathrm{C}$, we prepared $40 \mu \mathrm{m}$ sections using a cryostat. The sections, mounted on slides and cover-slipped using Permafluor (Shandon Inc, Pittsburgh, Pennsylvania), were observed with a Nikon ECLIPSE fluorescent microscope using filter G-1A (wavelengths of $546 \mathrm{~nm}$ for excitation and $565 \mathrm{~nm}$ for emission) for DiI and filter UV-1A (365 nm for excitation and $420 \mathrm{~nm}$ for emission) for FG. Only DRG-neuronal profiles labelled with a clear nucleus were counted. We determined the number of neurones labelled with either DiI or FG, and those double-labelled with both DiI and FG.

\section{Results}

Disc and ventral skin. As reported previously by Morinaga et $\mathrm{al}^{2}{ }^{2}$ neurones labelled with DiI transported from the L5L6 disc were distributed in the bilateral T13 to L5 DRGs and predominated in L1 to L3 DRGs (Table I). Neurones labelled with FG transported from the ventral skin were in
Table II. Total numbers of DiI-, FG- and DiI/FG double-labelled neurones in left DRGs T12 to S1 from ten rats which had FG applied to the dorsal rami of the T12 to $\mathrm{S} 1$ spinal nerves

\begin{tabular}{lccl}
\hline DRG & $\begin{array}{l}\text { Number of } \\
\text { DiI-labelled } \\
\text { neurones }\end{array}$ & $\begin{array}{l}\text { Number of } \\
\text { FG-labelled } \\
\text { neurones }\end{array}$ & $\begin{array}{l}\text { Number of DiI/FG } \\
\text { double-labelled } \\
\text { neurones }\end{array}$ \\
\hline T12 & 0 & 503 & 0 \\
T13 & 21 & 780 & 0 \\
L1 & 50 & 1956 & 0 \\
L2 & 48 & 2040 & 0 \\
L3 & 17 & 2163 & 0 \\
L4 & 7 & 2415 & 0 \\
L5 & 2 & 807 & 0 \\
L6 & 0 & 365 & 0 \\
S1 & 0 & 165 & 0 \\
Total & 145 & 11194 & 0 \\
\hline
\end{tabular}

the ipsilateral T12 to S1 DRGs. There were considerably more FG-labelled neurones than DiI-labelled neurones (Table I). The distribution of neurones labelled with DiI, FG, or both was random and there were no somatotopic features within the DRGs.

Neurones double-labelled with DiI and FG were found only in the L1 and L2 DRGs. The percentage of doublelabelled neurones among DiI-labelled neurones per DRG ranged from $0 \%$ to $40.0 \%$. Of the total 173 DiI-labelled neurones in the T13 to L5 DRGs, nine (5.2\%) were also double-labelled with FG (Table I). As shown in Figure 1, the double-labelled neurones were round or oval, with diameters varying from 15 to $50 \mu \mathrm{m}$ and most being of medium size $(30$ to $40 \mu \mathrm{m})$.

Disc and dorsal skin. We found DiI-labelled neurones in the bilateral T13 to L5 DRGs, and FG-labelled neurones transported from the dorsal skin of $\mathrm{T} 12$ to $\mathrm{S} 1$ dermatome in the ipsilateral T12 to S1 DRGs as with the ventral skin. There was no double-labelling of neurones (Table II).

\section{Discussion}

Patients who have a symptomatic degenerative intervertebral disc sometimes report pain in the groin. ${ }^{1-3}$ The groin area is innervated by the genitofemoral or ilioinguinal nerves in rats and in man. In rats, these are terminal branches of L1 or L2 spinal nerves. L4-L5 and L5-S1 disc 

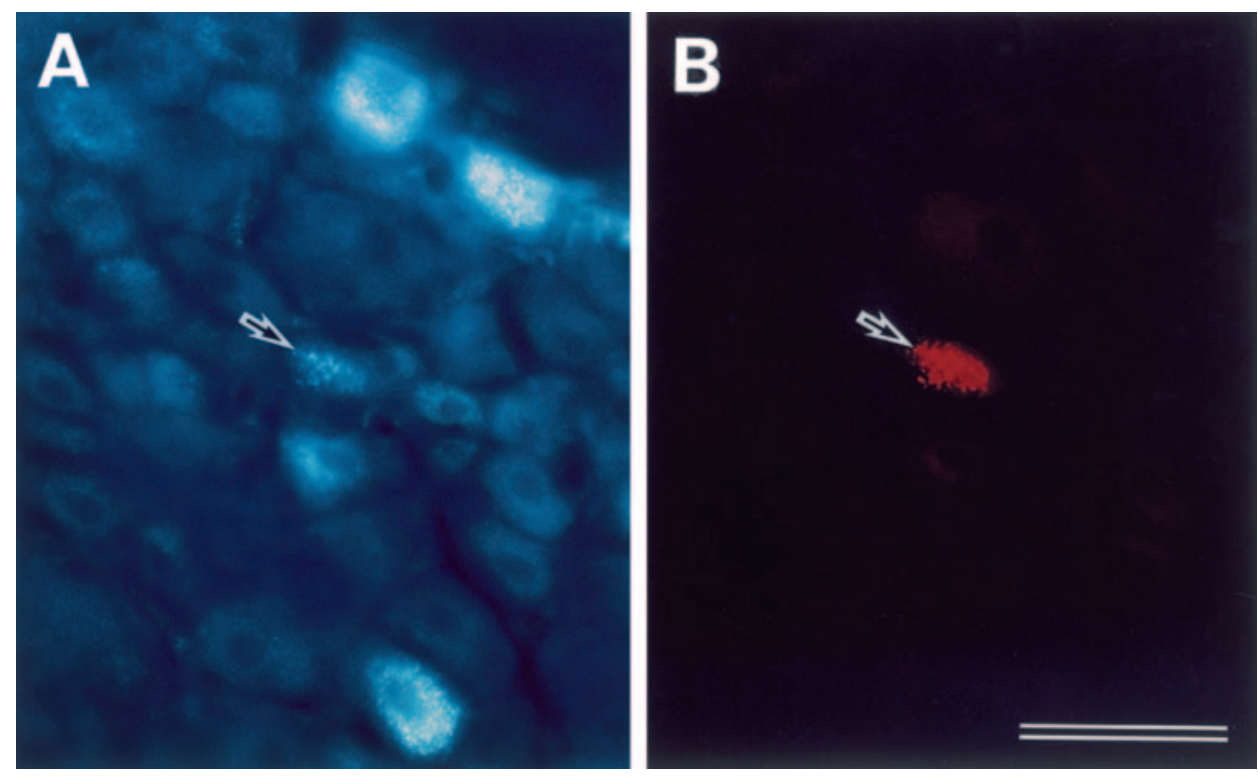

Fig. 1

Labelled neurones in the left L1 DRG after application of FG to the ventral skin viewed under ultraviolet filter optics $(365 \mathrm{~nm})$ for FG-labelling neurones (A) and rhodamine filter optics $(546 \mathrm{~nm})$ for DiI-labelling neurones $(\mathrm{B})$ The arrows indicate a neurone doublelabelled with FG and DiI. Many other neurones labelled with FG are seen in (A) (scale bar $=50 \mu \mathrm{m})$.

herniation can damage L5 and S1 spinal nerve roots. Pain in the groin in the lumbar disc lesion therefore is of a referred nature, and not radicular. Yukawa et $\mathrm{al}^{3}$ reported that of the 512 patients diagnosed with single lower lumbar disc herniation (L4-L5 and L5-S1), 21 (4.1\%) reported pain in the groin which disappeared after discectomy. Furthermore, Nakamura et $\mathrm{al}^{25}$ reported that pain in the groin associated with an L4-L5 disc lesion disappeared after selective local anaesthesia of the L2 nerve root.

Although not yet clarified there are two major conventional hypotheses for the neural mechanism of referred pain. First, the convergence-projection hypothesis initially proposed by Ruch $^{26}$ suggested that somatic and visceral afferents from each of the primary DRG neurones converged on the same dorsal horn neurones in the spinal cord. Several experimental studies have supported the authenticity of this hypothesis. ${ }^{27-29}$ Secondly, the concept of referred pain by Sinclair et $\mathrm{al}^{22}$ suggested that there were primary afferent fibres bifurcating into somatic and visceral structures.

Many studies have provided evidence for the existence of dichotomising axons of primary sensory neurones using double-labelling techniques, electrophysiological methods, or counting the number of DRG neurones and axons of proximal peripheral nerves on electron micrographs. ${ }^{11-21,30}$ The frequency of DRG neurones with dichotomising axons varies considerably among species, pairs of nerve fibres, and spinal segments. ${ }^{11-21}$ Electrophysiological studies show that $44 \%$ of somatic myelinated afferents bifurcate into the pudendal and sciatic nerves in the L6 segment of rats. ${ }^{21}$ The fact that there are 2.3 times as many peripheral axons as DRG neurones in rats also suggests the existence of dichotomising peripheral fibres. ${ }^{30}$ Despite these studies, some investigators are sceptical about the role of dichotomising fibres in referred pain because such fibres are rare. ${ }^{19,20}$

In our study, neurones labelled with DiI transported from the L5-L6 disc were in bilateral T13 to L5 DRGs, but pre-

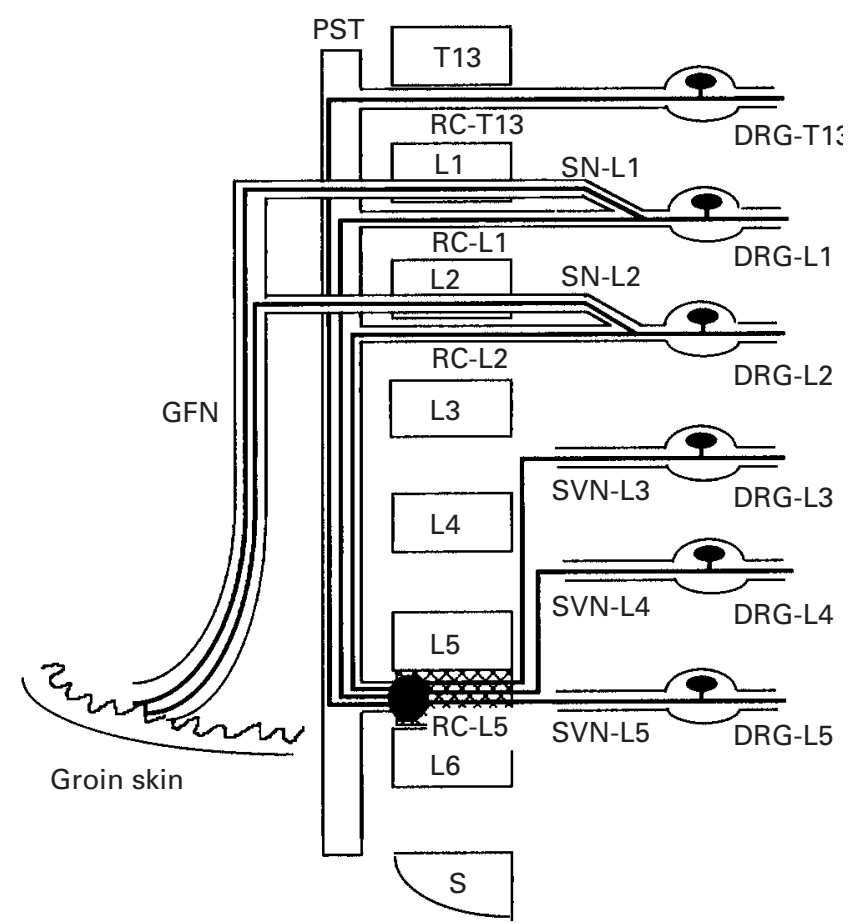

Fig. 2

Diagram showing the sensory pathways from the ventral portion of the L5L6 disc and neurones in the L1 and L2 DRG with dichotomising axons projecting to the ventral portion of the L5-L6 disc and to the groin skin. (GFN, genitofemoral nerve; PST, paravertebral sympathetic trunks; RC, ramus communicans; SN, spinal nerve; SVN, sinuvertebral nerve).

dominantly in L1, L2, L3 DRGs as previously reported. The presence of neurones double-labelled with DiI and FG in ipsilateral DRGs of L1 or L2 after application of FG to the ventral region of dermatomes, indicates that these neurones have peripheral axons which dichotomise into both the L5L6 disc and the ventral region of L1 and L2 dermatomes, that is, groin skin. Several groups have reported that nerve 
fibres passing through the sympathetic trunks innervate the ventral portion of lumbar intervertebral discs. ${ }^{31-36}$ Paravertebral sympathetic trunks and rami communicantes supply nerves to the lumbar intervertebral disc. ${ }^{32,33,35}$ In the rat, the dorsal portion of the L5-L6 disc is innervated by two distinct nervous pathways, by corresponding and adjacent segments (segmental-like, L3 to L6) or by distant segments (non-segmental, T13 to L2). ${ }^{37}$ In the segmental-like innervation, sensory nerve fibres from the ventral portion of the L5-L6 disc pass around the disc, and reach the L3 to L5 DRGs by sinuvertebral nerves. By contrast, in the non-segmental innervation, sensory nerve fibres enter the paravertebral sympathetic trunks directly or through the grey ramus of L5 and reach the DRGs from T13 to L2 through each ramus communicans of T13 to L2. The double-labelled neurones may have axons bifurcating into the L5-L6 disc and groin skin (Fig. 2).

The double-labelled neurones may indicate referred groin pain associated with lesions in the ventral portion of L5-L6 discs in rats. If there are dichotomising axons in man, a disc lesion may be responsible for referred groin pain. Ohtori et $\mathrm{al}^{37}$ reported that innervation of the dorsal portions of rat lumbar discs was by L1 and L2 DRG neurones, indicating that L1 and L2 DRG project afferent fibres to all lumbar discs. Therefore, there may be dichotomising sensory fibres connecting the groin area and the lumbar disc in other portions and levels of the lumbar discs, resulting in the referred groin pain. Yukawa et $\mathrm{al}^{3}{ }^{3}$ following a clinical study, reported herniations in the dorsal aspect of lower lumbar discs in patients with pain in the groin.

Our study has shown that $5.2 \%$ of neurones innervating the ventral portion of the L5-L6 disc had dichotomising axons projecting to the groin skin, suggesting that referred pain in the groin originating from the disc can be caused by convergence of afferent pathways at the DRG level.

We would like to thank Miss K. Kitajo for technical assistance.

No benefits in any form have been received or will be received from a commercial party related directly or indirectly to the subject of this article.

\section{References}

1. Jinkins FJ, Whitemore AR, Brandley WG. The anatomic basis of vertebrogenic pain and the autonomic syndrome associated with lumbar disk extrusion. Am J Roentgenol 1989;152:1277-89.

2. Morinaga T, Takahashi K, Yamagata M, et al. Sensory innervation to the anterior portion of lumbar intervertebral disc. Spine 1996;21:184851.

3. Yukawa Y, Kato F, Kajino G, Nakamura S, Nitta H. Groin pain associated with lower lumbar disc herniation. Spine 1987;22:1736-9.

4. Feinstein B, Langton JNK, Jameson RM, Schiller F. Experiments on pain referred from deep somatic tissues. J Bone Joint Surg [Am] 1954;36-A:981-97.

5. Hockaday JM, Whitty CW. Patterns of referred pain in the normal subjects. Brain 1967;90:481-96.

6. Inman VT, Saunders JB. Referred pain from skeletal structures. J Nerv Ment Dis 1944;99:660-7.

7. Kellgren JH. On the distribution of pain arising from deep somatic structures with charts of segmental pain areas. Clin Sci 1939;4:35-46.

8. Marks RC. Distribution of pain provoked from lumbar facet joints and related structures during diagnostic spinal infiltration. Pain 1989;39:3740
9. McCall IW, Park WM, O'Brien JP. Induced pain referral from posterior lumbar elements in normal subjects. Spine 1979;4:441-6.

10. Murphey F. Sources and patterns of pain in disc disease. Clin Neurosurg 1968;15:343-51.

11. Alles A, Dom RM. Peripheral sensory nerve fibers that dichotomize to supply the brachium and the pericardium in the rat: a possible morphological explanation for referred cardiac pain? Brain Res 1985;342:3825 .

12. Borges L, Moskowitz MA. Do intracranial and extracranial trigeminal afferents represent divergent axon collaterals? Neurosci Lett 1983;35:265-70.

13. Dawson NJ, Schmid H, Pierau FK. Pre-spinal convergence between thoracic and visceral nerves of the rat. Neurosci Lett 1992;138:149-52.

14. Pierau FK, Fellmer G, Taylor DC. Somato-vesceral convergence in cat dorsal root ganglion neurones demonstrated by double-labelling with fluorescent tracers. Brain Res 1984;321:63-70.

15. Schmid H, Taylor DC, Pierau FK. Tracing of sensory neurones and spinal motoneurones of the pigeon by injection of fluorescent dyes into peripheral nerves. Cell Tissue Res 1983;232:9-19.

16. Taylor DC, Pierau FK. Double fluorescence labelling supports electrophysiological evidence for dichotomizing peripheral sensory nerve fibers in rats. Neurosci Lett 1982;33:1-6.

17. Taylor DC, Pierau FK, Schmid H. The use of fluorescent tracers in the peripheral sensory nervous system. J Neurosci Methods 1983;8:211-24.

18. Bahr R, Blumberg H, Janig W. Do dichotomizing afferent fibers exist which supply visceral organs as well as somatic structures? A contribution to the problem of referred pain. Neurosci Lett 1981;24:25-8.

19. Devor M, Wall PD, McMahon SB. Dichotomizing somatic nerve fibers exist in rats but they are rare. Neurosci Lett 1984;49:187-92.

20. Habler HJ, Janig W, Koltzenburg M. Dichotomizing unmyelinated afferents supplying pelvic viscera and perineum are rare in the sacral segments of the cat. Neurosci Lett 1988;94:119-24.

21. Pierau FK, Taylor DC, Abel W, Friedrich B. Dichotomizing peripheral fibers revealed by intracellular recording from rat sensory neurones. Neurosci Lett 1982;31:123-8.

22. Sinclair DC, Weddell G, Feindel WH. Referred pain and associated phenomena. Brain 1948;71:184-211.

23. Takahashi Y, Morinaga T, Nakamura S, et al. Neural connection between the ventral portion of the lumbar intervertebral disc and the groin skin. J Neurosurg 1996;85:323-8.

24. Takahashi Y, Nakajima Y, Sakamoto T. Dermatome mapping in the rat hindlimb by electrical stimulation of the spinal nerves. Neurosci Lett 1994;168:85-8.

25. Nakamura S, Takahashi K, Takahashi Y, Yamagata M, Moriya H. The afferent pathways of discogenic low back pain. J Bone Joint Surg [Br] 1996;78-B:606-12.

26. Ruch TC. Visceral sensation and referred pain. In: Fulton JF, ed. Howell's textbook of physiology, 15th edition. Philadelphia: WB Saunders, 1946:385-401.

27. Foreman RD, Weber RN. Responses from neurons of the primate spinothalamic tract to electrical stumulation of afferents from the cardiopulmonary region and somatic structures. Brain Res 1980;186:463-8.

28. Rucker HK, Holloway JA. Viscerosomatic convergence onto spinothalamic tract neurons in the cat. Brain Res 1982;243:155-7.

29. Selzer M, Spencer WA. Convergence of visceral and cutaneous afferent pathways in the lumbar spinal cord. Brain Res 1969;14:331-48.

30. Langford LA, Coggeshall RE. Branching of sensory axons in the peripheral nerve of the rat. J Comp Neurol 1981;203:745-50.

31. Bogduk N, Tynan W, Wilson AS. The nerve supply to the human lumbar intervertebral discs. J Anat 1981;132:39-56.

32. Bogduk N. The innervation of the lumbar spine. Spine 1983;8:286-93.

33. Groen GJ, Baljet B, Drukker J. Nerves and nerve plexuses of the human vertebral column. Am J Anat 1990;188:282-96.

34. Paris SV. Anatomy as related to function and pain. Orthop Clin North Am 1983;14:475-89.

35. Stilwell DL Jr. The nerve supply of the vertebral column and its associated structures in the monkey. Anat Rec 1956;125:139-69.

36. Weinstein J, Claverie W, Gibson $\mathbf{S}$. The pain of discography. Spine 1988; $13: 1344-8$

37. Ohtori S, Takahashi Y, Takahashi K, et al. Sensory innervation of the dorsal portion of the lumbar intervertebral disc in rats. Spine 1999;24:2295-9. 